NASA Technical Memorandum 102474

AIAA-90-0722

\title{
and Space Station Photovoltaic Panels Plasma Interaction Test Program: Test Plan and Results
}

Henry K. Nahra, Marian C. Felder, Bernard L. Sater, and John V. Staskus

Lewis Research Center

Cleveland, Ohio

Prepared for the 28th Aerospace Sciences Meeting sponsored by the American Institute of Aeronautics and Astronautics Reno, Nevada, January 8-11, 1990

\section{N/SA}




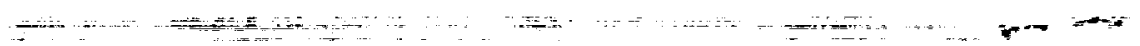




\title{
THE SPACE STATION PHOTOVOLTAIC PANELS PLASMA INTERACTION TEST PROGRAM: TEST PLAN AND RESULTS
}

\author{
Henry K. Nahra, Marian C. Felder, Bernard L. Sater and John V. Staskus \\ National Aeronautics and Space Administration \\ Lewis Research Center \\ 21000 Brookpark Rd. \\ Cleveland, Ohio 44135
}

\begin{abstract}
This paper addresses the Plasma Interaction Test performed on two Space Station solar array panels. This includes a discussion of the test requirements, test plan, experimental set-up and test results. It was found that parasitic current collection was insignificant $(0.3 \%$ of the solar array delivered power.) The measured arcing threshold ranged from -210 to -457 Volts with respect to the plasma potential. Furthermore, the dynamic response of the panels showed the panels time constant to range between 1 and $5 \mu \mathrm{s}$, and the panels capacitance to be between .01 and $.02 \mu \mathrm{F}$.
\end{abstract}

\section{Introduction}

NASA-Lewis Research Center is responsible for providing the power on the Space Station Freedom. The initial power system of the space station consists of four Photovoltaic (PV) Power Modules capable of delivering $75 \mathrm{KW}$ of conditioned power to the users. The PV power module baseline design (Fig. 1) consists of two flexible-deployable solar array assemblies for power generation, batteries for energy storage, a thermal control system for the thermal conditioning of the batteries and power conversion devices, two rotational $\beta$ gimbals for solar pointing during the seasonal variations and the truss structure which provides the structural support. 1

\section{The LEO Space Environment}

The Space Station Freedom will be operating in the Low Earth Orbital (LEO) environment at altitudes of

Copyright (C) 1990 by the American Institute of Aeronautics and Astronautics, Inc. No copyright is asserted in the United States under Title 17, U.S. Code. The U.S. Government has a royalty-free license to exercise all rights under the copyright claimed herein for Governmental purposes. All other rights are reserved by the copyright owner.
180 to 250 miles. The natural LEO environment consists of residual neutral species, ionized species which constitute the plasma environment, radiation, micrometeoroid and orbital debris, and ionizing radiation. The components of the natural environment present a wide variety of interactions with the Space Station Freedom and its operating power system. The near equatorial orbit plasma environment consists of plasma density that ranges from $-10^{5}$ ions $/ \mathrm{cm}^{3}$ during the sunshade period to $-10^{6}$ ions $/ \mathrm{cm}^{3}$ during the sunlight period of the orbit. The polar plasma environment is comprised of lower charged particle density, and exhibits energetic auroral electron flux which could be responsible for charging of surfaces. 2

\section{Test Objectives}

Due to the concern of the possible plasma effects on the solar array operating voltage and the interactions between the solar array of the PV module and the plasma environment in the near equatorial and polar orbits, the PV Plasma Interaction Test (PVPIT) was planned in order to 1) evaluate the effect of the plasma environment on the operating voltage of the array, 2) determine the arcing potential for different plasma densities, 3) determine the effect of the parasitic currents collected on the panels' performance, 4) determine the effect of auroral electron surface charging on the array, 5) measure the potential difference generated by the panel pair during the out-of-eclipse thermal transient, and 6) determine the dynamic response of the panels due to capacitance coupling with the plasma sheath. 


\section{Description of The Test Article}

The test article consists of two active solar array panels in series. As shown in Fig. 2, each panel contains 200 active $8 \times 8 \mathrm{~cm}$ silicon solar cells for voltage and current generation, flexible substrate which contains the copper photo-etched interconnecting circuit, graphite epoxy-aluminum wrapped stiffeners for additional structural stability, aluminized hinges, and power leads. The two panels are hinged together by a hinge pin, are electrically connected in series and are capable of producing a maximum power voltage of approximately $170 \mathrm{~V}$ and current of 0.9 amperes under reduced illumination of 0.3 sun ( -2.6 amperes at full sun illumination.) Fig. 3 illustrates an I-V curve for the two panels measured inside the vacuum tank.

\section{Iest Bequirements}

The test requirements given to the designers of the PVPIT test set up (Operation and Special Project Division) included four sets of requirements. The first consisted of requirements for the sample physical configuration and power accommodation, requirements for mounting and handling of the two solar array panels, requirements for outgassing directed toward ensuring clean vacuum environment during testing, and thermal requirements to ensure that the operating temperature of the cells did not exceed $40^{\circ} \mathrm{C}$ during testing. The second consisted of requirements for plasma environment simulation for near equatorial and polar orbits, and solar flux simulation requirements which require up to 0.3 sun intensity. The third included requirements for data collection capabilities which in turn included provisions for I-V characteristics and plasma diagnostics measurements, current, voltage and temperature measurements, requirements for panels loading and bias power, requirements for performance of a small scale plasma interaction test in order to verify the performance of the test equipment, and finally requirements for an out-of-eclipse simulation test in order to measure the higher voltage generated by the panels on entering the sunlight period of the orbit. The fourth included requirements for test hardware used to determine the dynamic response of the array panels.

\section{Iest Plan}

The PVPIT test plan consists of 7 major tests. The first, Plasma Characterization test which uses Kap- ton $\left({ }^{*}\right.$ * dummy panels is directed toward the overall system checkout. The second, Small scale Plasma Interaction Test, is aimed toward testing 12 cell string in the plasma and auroral electron flux environment in order to verify the adequacy of the testing procedures planned for the full scale panels without risking them. Preliminary parasitic current collection, arcing threshold potential and charging measurements are made in this test at density levels of $10^{2}, 10^{4}, 10^{6}$ ions/ $\mathrm{cm}^{3}$. The third test is primarily for Parasitic Current Collection Measurements using the full scale panels at five densities ranging from $10^{2}$ to $10^{6}$ ion $/ \mathrm{cm}^{3}$. The fourth test consists of Arcing Potential Threshold Measurements as a function of the plasma density for the same range as the parasitic current collection test. The fifth test consists of the Measurement of the Effect Of Charging on the panels at two plasma densities of $10^{2}$ and $10^{3}$ ions $/ \mathrm{cm}^{3}$. Electron flux is simulated in this test by electron guns that are capable of irradiating a portion of the two panels. These electron guns are monoenergetic (up to $10 \mathrm{KeV}$ electron beam) and capable of generating electron flux on the order of nanoamps $/ \mathrm{cm}^{2}$. The sixth test comprises the Out-of-eclipse Simulation that is directed toward measuring the transient high potential generated by the sudden solar energy load on the solar cells. The plasma densities for this test are $10^{2}$ and $10^{6}$ ions $/ \mathrm{cm}^{3}$. The seventh test is directed towards determining the Dynamic Response of the panels to switching loads and how it may be affected by the plasma sheath. Prior to the third test and after each of the following tests, the I-V characteristics curve will be measured for the two panels in order to detect any degradation of performance due to any of the four tests that are planned for the full size panels.

\section{Iest Confiauration}

The test equipment within the vacuum tank shown in Fig. 4 consists of the structural cage that supports the different systems used for sunlight simulation, plasma density, electron fluence, and required thermal environment. The light intensity of .3 sun is generated by the light bank of 252 low voltage lamps. The lamps were configured into 3 independent strings in order to provide independent adjustment to produce the desired light intensity and maintain a $+/-10 \%$ variation

\footnotetext{
* Registered Trademark of E. I. DuPont de Nemours and Co., Inc.
} 
in intensity over an area of approximately $14 \mathrm{ft}$ by 2.5 $\mathrm{ft}$.

Two types of plasma sources were used to generate plasma at low and high densities. Six hot filament plasma sources were mounted throughout the supporting cage structure. As Argon gas is passed over the hot filament in the chamber, electrons emitted by the filament collide with the Argon neutral atoms and create the plasma. To increase the probability of collision, uniform magnetic fields are used to lengthen the electron path before impinging on the anode. These sources were used to generate plasma at densities between $10^{2}$ and $10^{4}$ ions $/ \mathrm{cm}^{3}$. The high density $\left(10^{5}\right.$ to $10^{6}$ ions $/ \mathrm{cm}^{3}$ ) plasma was generated by a single hollow cathode device located at one end of the vacuum tank. Argon is passed through a tube at high temperature thereby inducing a catalytic reaction which generates the plasma. The plasma density was determined by measuring the current-voltage profile obtained from 11 spherical Langmuir probes mounted about the cage. The voltage to each probe was applied through a pre-programmed range and the resulting current was measured. From the crossover point of the $I-V$ curves, electron and ion temperatures and plasma density were determined. The auroral electron flux for the charging experiment was produced by four electron filament sources mounted above the PV test article, two facing each side of the panels. The electrons are electrostatically accelerated and ejected from the source.

Real time voltage and current data were recorded outside the tank by the data acquisition system along with arcs generated during the experiments. Additionally, real time temperature data of the cold wall and the test article were recorded. Voltage at the terminals of the panels was measured by two independent means. Two non-contacting Trek probes were used to measure the voltage. These voltages, in turn, were compared to voltages obtained via meters attached to the panel terminals through connections to the bias voltage supply.

For the dynamic response test, circuitry was added to simulate the sequential shunt unit (SSU) to be employed for regulating the DC bus voltage on Space Station Freedom. The DC bus voltage is regulated by shorting out panels in excess of station power needs using a power MOSFET switch in the SSU that oper- ates at $20 \mathrm{kHz}$ with pulse width modulation control capability. Knowing the dynamic response characteristics of the panels is important for design purposes.

\section{Iest Results}

During the Plasma Characterization Test, the aforementioned 5 plasma densities were generated, electron guns were run, the cold wall system was successfully operated, and the data acquisition system was operated with monitoring thermocouples on the dummy panels and the Langmuir probes installed on the structural cage. Vacuum of $10^{-6}$ torr was achieved and maintained. At lower plasma densities, the spatial variation in plasma density did not exceed half an order of magnitude. At the highest density, nominally $10^{6}$ ions $/ \mathrm{cm}^{3}$, the variation measured approximately a factor of ten between each end of the panel. The Small Scale Plasma Interaction Test was performed. Results from this test showed that the measured current collection was on the order of milliAmps at $170 \mathrm{~V}$ at a density level of $10^{6}$ ions $/ \mathrm{cm}^{3}$. The results also showed that arcing did not occur even at significantly higher negative potentials than the plasma relerence.

Results from the Parasitic Current Collection Test of the full scale panels, depicted in Fig. 5, showed that the ion currents collected from the plasma increase with the plasma density when the positive terminal of the two panel circuit was grounded. The results also showed that the collected electron current increased with the plasma density when the negative terminal of the panel circuit was grounded leaving the positive terminal at $-170 \mathrm{~V}$ potential above the plasma ground. If it is assumed that all the parasitic currents are collected at the most negative cell (for ion currents) or the most positive cell (for electron currents), then a worst case computation of parasitic power loss is less than $25 \mathrm{~W}$ per photovoltaic wing, or less than $.3 \%$ of the total power provided by each wing.

Arcing Potential Threshold was measured at three density levels and was shown to range between -210 and $-457 \mathrm{~V}$ as measured at the negative terminal of the panel circuit. The results are shown in Table $I$. These measurements were made under illuminated conditions when the array panels were operating at their maximum power point of approximately $176 \mathrm{~V}$. The panels were then biased negatively with respect to plasma potential until arcs were recorded. The voltage transients associated with the arcs were in the 1 to 
$4 \mathrm{~V}$ range and on the order of microseconds in duration. The transients indicated the change in the positive or negative terminal with respect to ground. A linear relationship did not appear to exist between the arcing onset potential and the plasma density. Charging effects were not detected. Varying the electron flux and the electron energy did not result in measurable effects on the array terminal voltages, either steady-state or as transients. Table II displays the results of the Out-Of-Eclipse Simulation Test which was intended to measure the potential differences generated by the sudden thermal transient when the array enters the sunlight portion of the orbit. No effect from the plasma was seen on the voltages measured. The predicted Voc for a 400 cell panel pair operating at 1 sun intensity at the experimental temperature is $294 \mathrm{~V} .{ }^{3}$ The voltage is then adjusted for the $70 \%$ reduction in sunlight intensity present during the experiment to yield $285 \mathrm{~V}$. A difference of $9 \%$ then exists between predicted Voc and that obtained experimentally. This difference arises from the use of non-current matched solar cells in the test article and from error in adjusting the voltage for a reduction in sunlight intensity.

The Dynamic Response Test showed that the solar cell panels exhibited a time constant that ranged from I to 5 microsecond (as measured from typical voltage-time response curve shown in Fig. 6) due to a step change in loads, i.e. $220 \mathrm{ohms}$ (maximum power load) $10110 \mathrm{ohms}$. Tests indicate the array panel capacitance is about 0.01 to 0.02 microfarads and that it is not affected by the plasma sheath at up to $10^{6}$ ions/ $\mathrm{cm}^{3}$ density. (For 1 sun illumination the response would be about three times faster because of the higher current output of the solar cells.) In addition, as shown in table III, there was no noticeable change in the dynamic response for positive or negative grounding or floating array conditions.

Flash tests were conducted following each series of tests. The I-V characteristics of the array panels did not change as a result of the plasma exposure, within the measurement error of the flash testing system, $+/-$ $3 \%$. Table IV presents Voc, Isc, and Pmax following each test.

\section{Cencludina Remarks}

This paper presented the requirements, test plan and the results of the PV Plasma Interaction Test which was conducted to determine the plasma effects on solar array operating characteristics. Results of this testing indicate that insignificant parasitic power loss is expected when Space Station Freedom's solar arrays are operating at nominal voltage. Also it was found that arcing is not expected at an operating voltage of $160 \mathrm{~V}$. Addtionally, no power degradation was experienced by the solar array panels as a result of operating in a plasma environment. During Phase $C / D$ of the Space Station Program further plasma testing will be performed on solar array panels which will most closely resemble actual flight hardware.

\section{Acknowledaments}

The authors wish to thank Mr. Henry B. Curtis of the Photovoltaic Branch for performing the I-V characteristic measurements of the panels. Moreover, the authors are grateful to the members of the Spacecraft Environment Office of the Power Technology Division and the Energy and Spacecraft Branch of the Test and Installation Division for their tremendous support to this project.

\section{Beferences}

1. "Power System Description Document," Space Station Freedom Electric Power System, WP-04, Contract NAS3-25082, DR SE-02, Rockwell International, Rocketdyne Division, Canoga Park, CA, 91303, July 3, 1989.

2. "Space Station Program Natural Environment Definition for Design," Space Station Program Office, SSP 30425.

3. Rauschenbach, H. S., Solar Cell Array Design Handbeok, Van Nostrand Reinhold Co., NY, NY, 1980. 


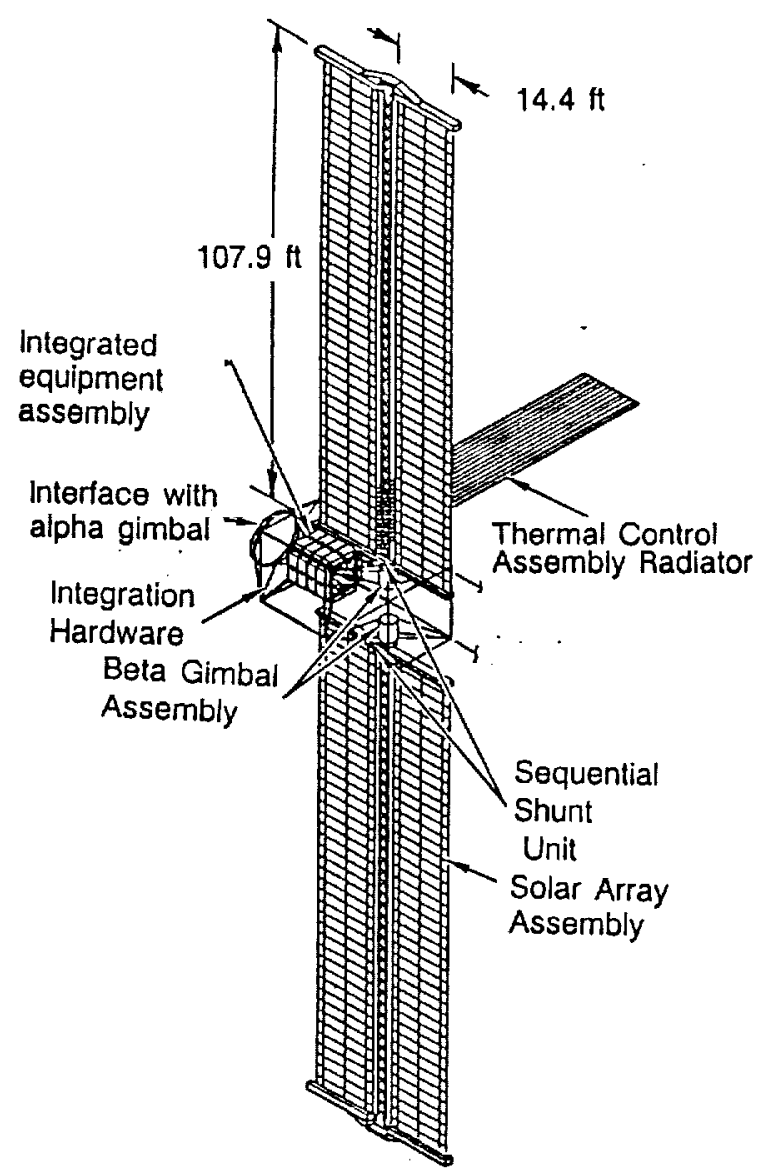

Figure 1. Illustration of the Photovoltalc Power Module and lis subassemblies

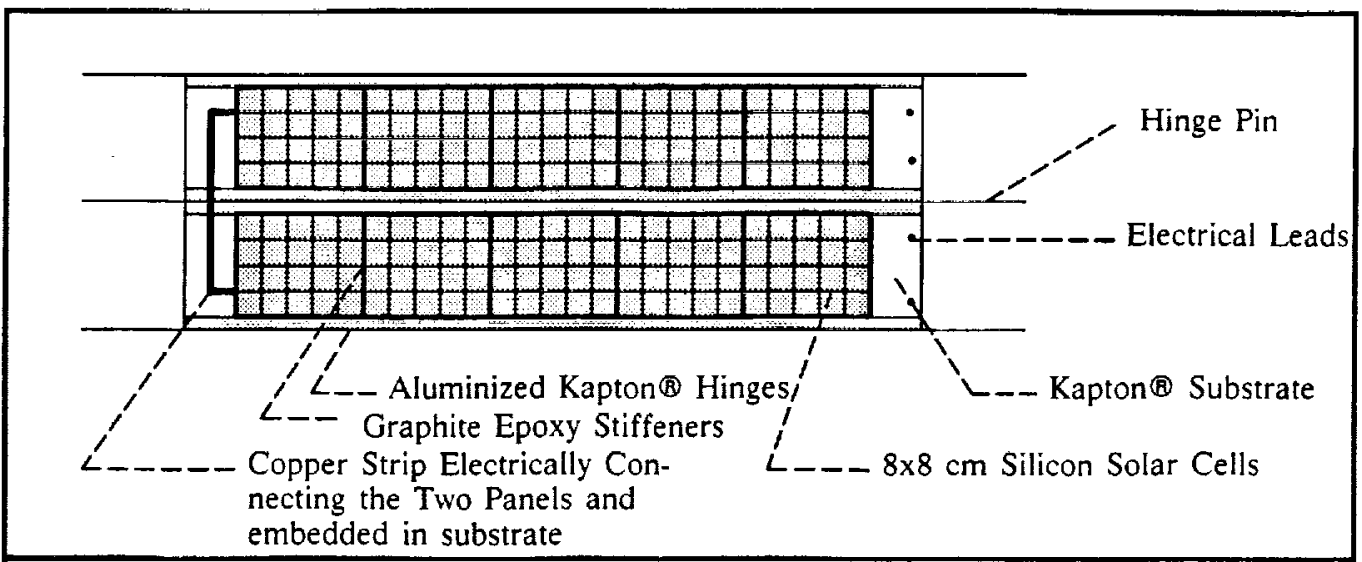

Figure 2. Schematic of the Two Solar Array Panels Tested in the Plasma Chamber 


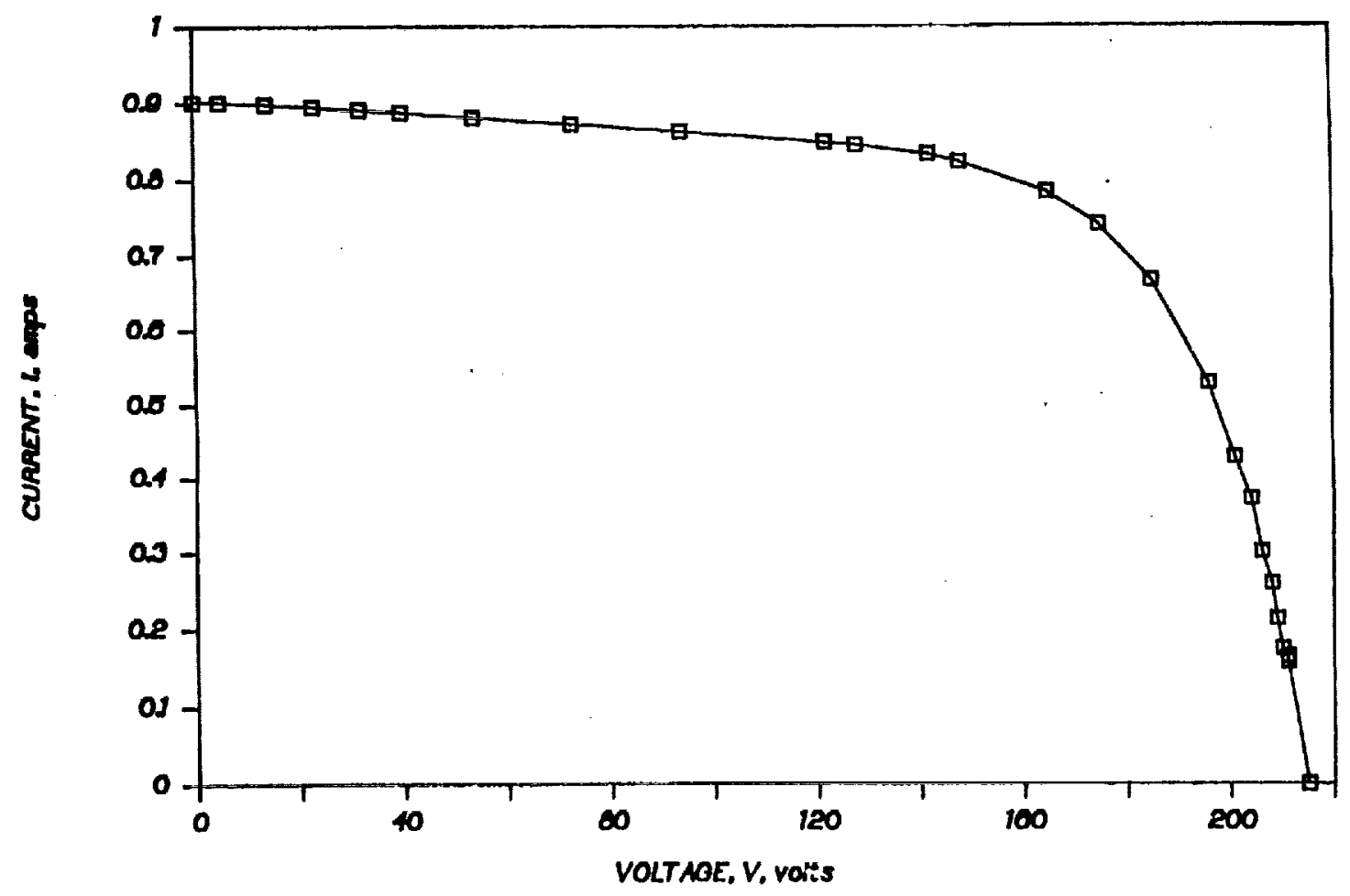

Figure 3. I-V Characteristic Curve of the Two Panels Generated Under Reduced Illumination

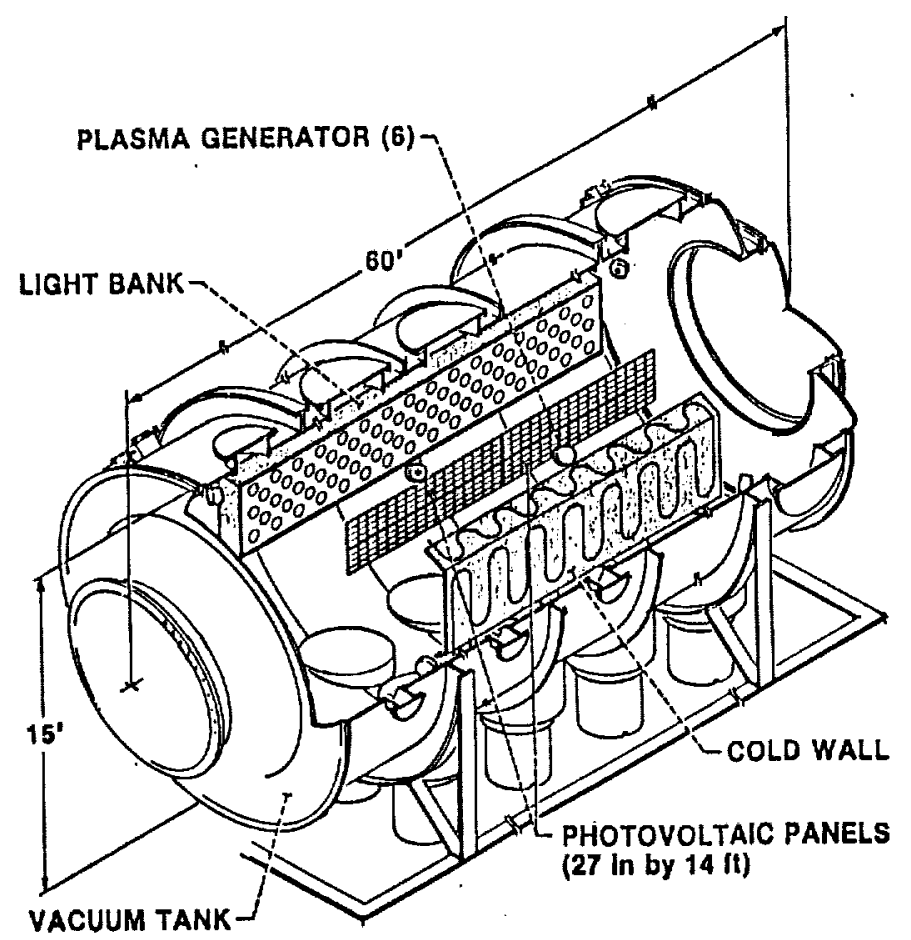

Figure 4. Schematic of the Experimental Set-up of the Plasma Interaction Test 
Parasitic Current Collected by Photovoltaic Panels Operating at Maximum Power Point $(\mathrm{V}=176 \mathrm{~V})$ as a Function of Plasma Density

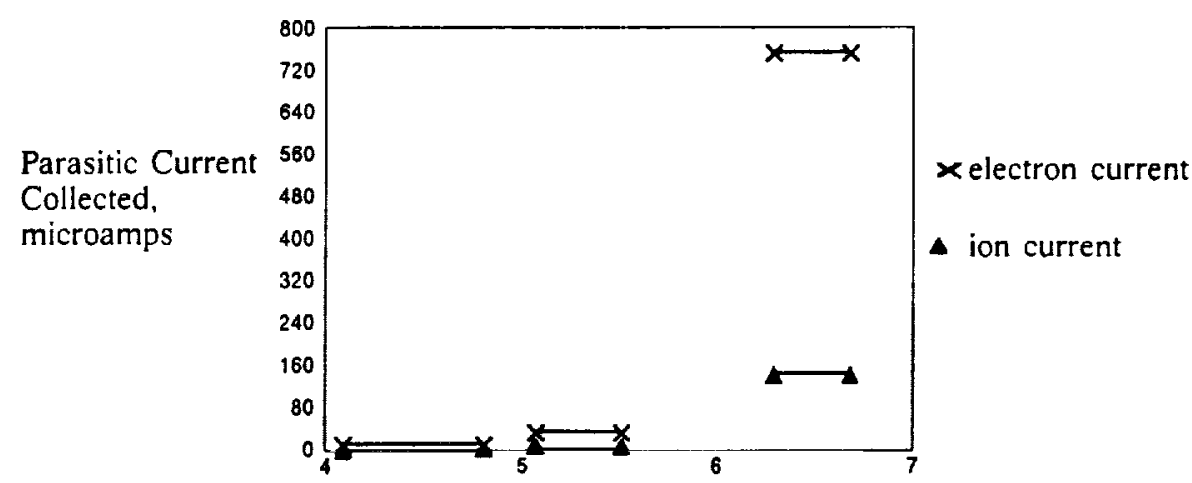

Log Plasma Density, ions $/ \mathrm{cm}^{3}$

Figure 5. Results of Parasitic Current Collection Tests

\begin{tabular}{|c|c|}
\hline $\begin{array}{l}\text { Plasma Density } \\
\text { ions } / \mathrm{cm}^{3}\end{array}$ & $\begin{array}{l}\text { Arcing Onset Potential } \\
\mathrm{V}\end{array}$ \\
\hline $1.74 \times 104$ to $1.22 \times 105$ & -457 \\
\hline $9.07 \times 104$ to $4.64 \times 105$ & -210 \\
\hline $1.72 \times 106$ to $9.73 \times 106$ & -245 \\
\hline \\
\hline
\end{tabular}

\begin{tabular}{|c|c|c|}
\hline $\begin{array}{l}\text { Plasma Density } \\
\text { ions } / \mathrm{cm}^{3}\end{array}$ & $\begin{array}{l}\text { Array Open Circuit } \\
\text { Voltage V }\end{array}$ & $\begin{array}{c}\text { Array Load } \\
\text { Voltage V }\end{array}$ \\
\hline $7.67 \times 102$ to $7.76 \times 10^{3}$ & 261 & 211 \\
\hline $2.12 \times 106$ to $1.21 \times 107$ & 262 & 213 \\
\hline Table Il. Results from the Out-of-Eclipse Simulation Testing \\
\hline
\end{tabular}




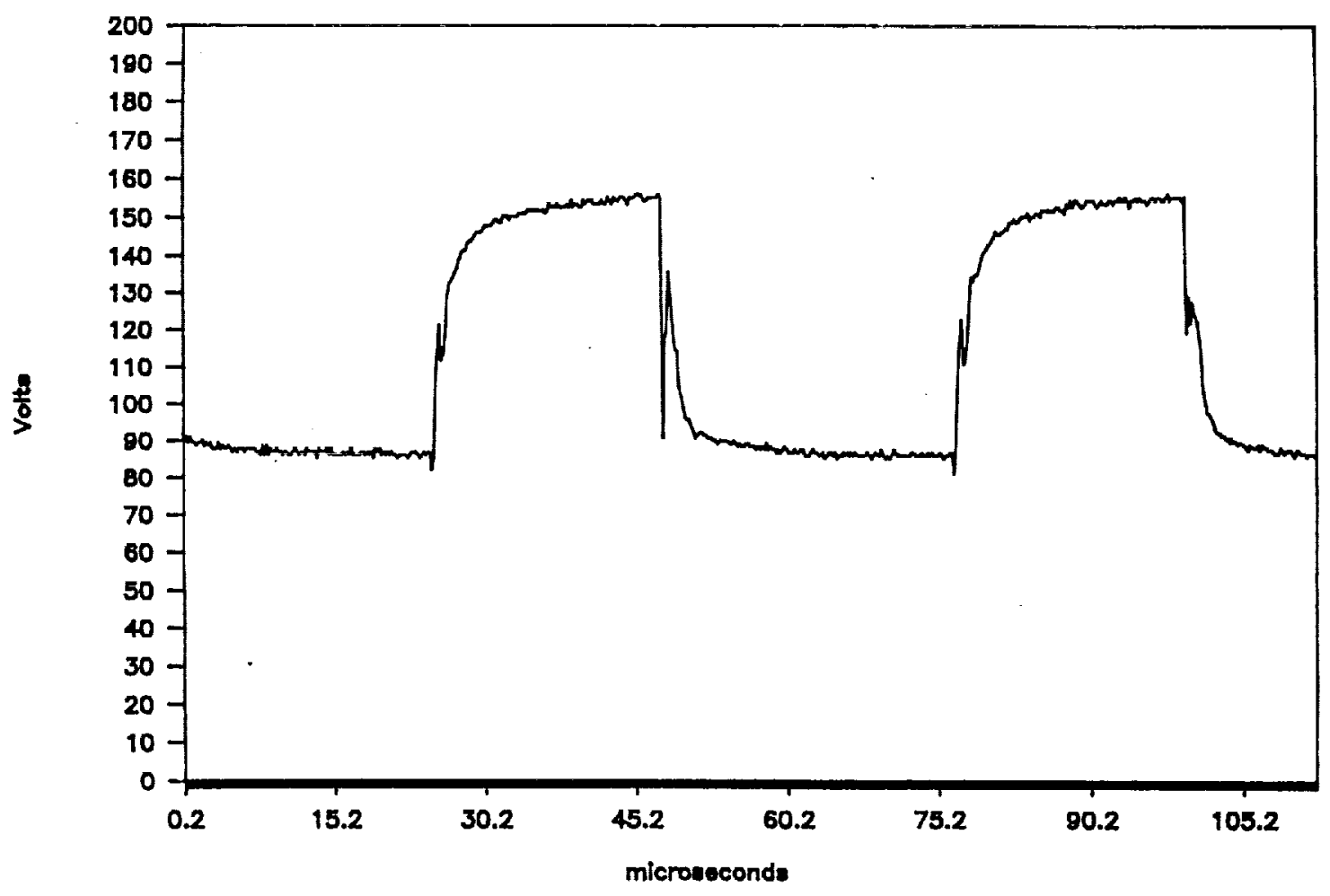

Figure 6. Voltage-Time Response of the Panels Due to a Step Change in Load

\begin{tabular}{|l|c|c|}
\hline \multicolumn{1}{|c|}{ Time Constant } & $\begin{array}{c}\text { During Voltage } \\
\text { Rise }(\mu \mathrm{s})\end{array}$ & $\begin{array}{c}\text { During Voltage } \\
\text { Fall }(\mu \mathrm{s})\end{array}$ \\
\hline Measurement Condition & 1.5 & Not recorded \\
B) Floating & 3.3 & Not recorded \\
C) + Side grounded & 2.0 & 2.0 \\
D) + Side grounded with $.02 \mu \mathrm{F}$ added & 4.0 & 3.0 \\
E) - Side grounded & 2.5 & 1.8 \\
F) - Side grounded with $.02 \mu \mathrm{F}$ added & Not recorded & Not recorded \\
\hline $\begin{array}{l}\text { Table III. Results of Time Constant Measurements Made During the Dynamic } \\
\text { Response Testing. }\end{array}$
\end{tabular}




\begin{tabular}{|c|c|c|c|c|c|c|}
\hline Test Condition & \multicolumn{2}{|c|}{ Voc, V } & \multicolumn{2}{|c|}{ Isc, $A$} & \multicolumn{2}{|c|}{$P \max , W$} \\
\hline & Panel A & Panel B & Panel A & Panel B & Panel A & Panel B \\
\hline Pre-Test & 117.52 & 118.91 & 2.548 & 2.518 & 192.66 & 193.26 \\
\hline $\begin{array}{l}\text { Post Parasitic } \\
\text { Current Col- }\end{array}$ & 119.27 & 119.31 & 2.457 & 2.464 & 182.93 & 187.62 \\
\hline Post Arcing & 119.90 & 120.46 & 2.606 & 2.590 & 198.60 & 202.30 \\
\hline Post Out-of-Eclipse & 120.55 & 121.06 & 2.637 & 2.608 & 206.43 & 209.71 \\
\hline
\end{tabular}




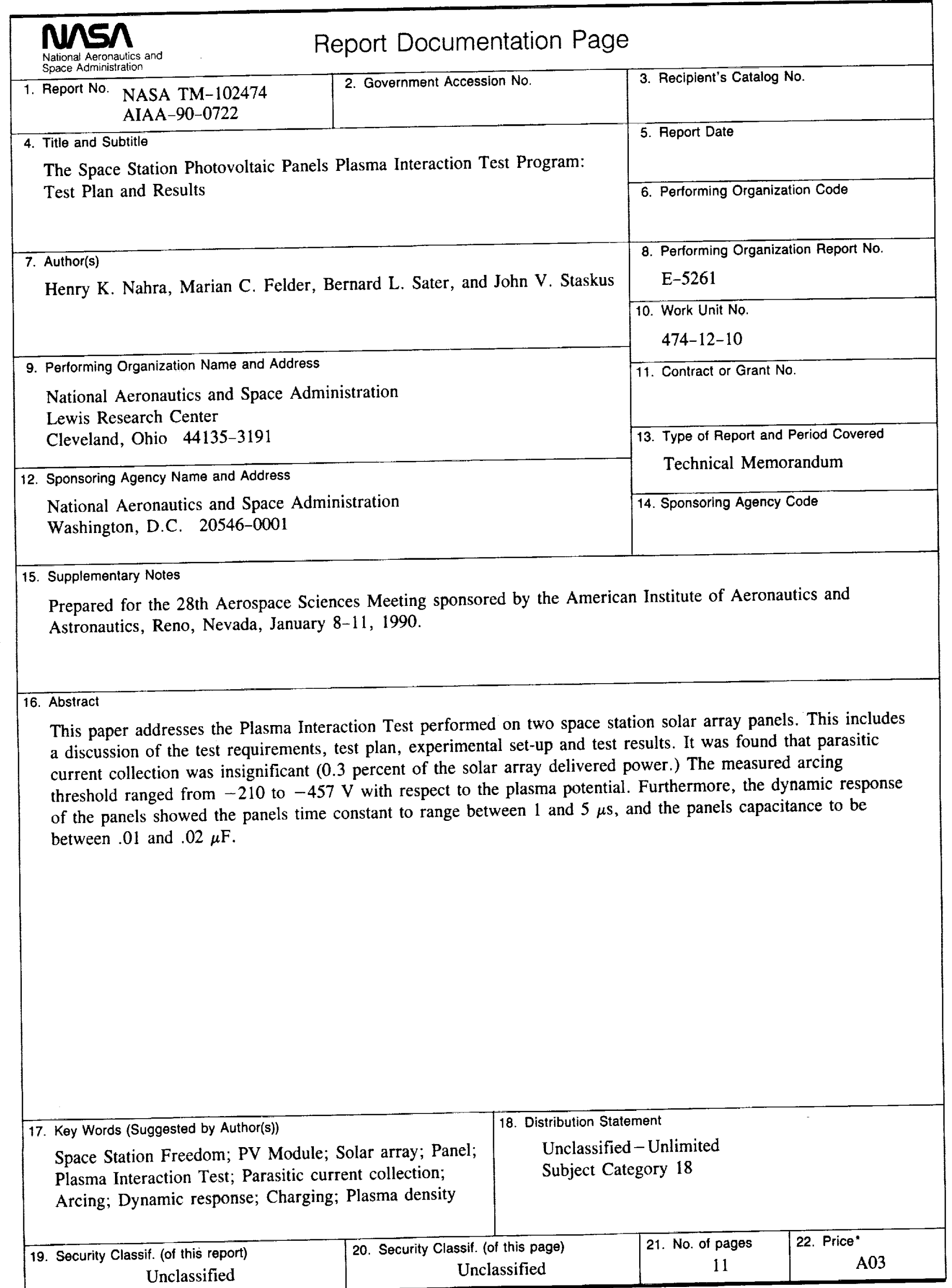

